\title{
Double side interior permanent magnet linear synchronous motor and drive system
}

\begin{abstract}
Linear motor has been applied in various fields such as factory and office automation. A linear motor differs from a rotational motor, in which it has a simpler structure. Linear Synchronous Motor is one of the types of linear motor and its application is very wide which is from the small application (i.e. industrials automation) to large application (i.e. maglev transportation) [1]. The thrust which is generated by linear motor is high, even with the size of the motor is small [2]. This is the feature of the linear motor compared to rotational motor where a gear is needed to change the rotational movement to the linear movement. Therefore the linear motor can reduce the mechanical losses. This paper discuss on the proposal of Double Side Interior Permanent Magnet of Linear Synchronous Motor (DIPM-LSM). The structure and three dimensions of magnetic circuit of DIPM-LSM are discussed. This type of DIPM-LSM can be driven by sinusoidal and pulse voltage input. The three phase two coils excitation-driving mode of open loop drive systems are also been discussed.
\end{abstract}

Keyword: Driving system; Interior permanent magnet linear synchronous motor; Magnetic circuit; Thrust characteristics 